
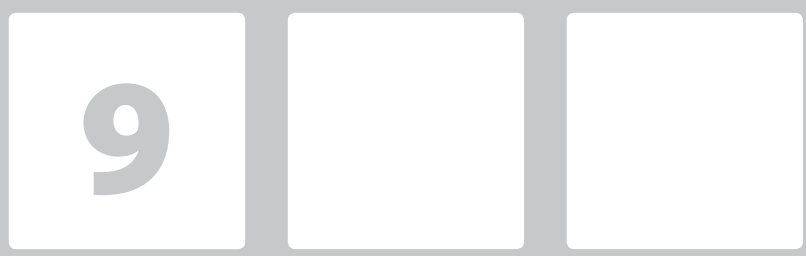

\title{
AFINAL, RH PARA QUÊ? \\ UM ESTUDO EM ECONOMIA PERIFÉRICA
}

\section{After All, What's Human Resources For? A Study in Peripheral Economics}

\section{Anderson de Souza Sant'Anna}

Dr. Prof. e Pesquisador. Fundação Dom Cabral (FDC).

Belo Horizonte (MG). Brasil. e-mail:anderson@fdc.org.br

\section{Daniela Martins Diniz}

Dra. Prof. e Pesquisadora. Univ. Federal de São João del Rei (UFSJ)

Belo Horizonte (MG).Brasil.e-mail:danidiniz09@yahoo.com.br

\section{Susan Mara Gaudensi Paiva}

Mestre. Gerente de Projetos. Fundação Dom Cabral (FDC).

São Paulo (SP). Brasil. e-mail: susan@fdc.org.br

\section{RESUMO}

O propósito deste artigo é apresentar resultados de uma pesquisa direcionada a investigar papeis e competências requeridas a profissionais de Recursos Humanos $(\mathrm{RH})$ na realidade de um país de economia periférica1 (o Brasil). Para tal, procedeu-se revisão teórica que explora relações entre estudos nacionais e internacionais sobre a função $\mathrm{RH}$ e o construto "competências". Em termos metodológicos, a pesquisa pode ser caracterizada como um estudo de caso de natureza qualitativa, envolvendo a realização de 32 entrevistas em profundidade com presidentes e diretores de empresas atuantes no Brasil, bem como com especialistas brasileiros na área de gestão de pessoas. Os resultados revelam percepções unânimes quanto à prevalência de modelos de gestão de pessoas centrados na "dimensão operacional", sinalizando discrepâncias entre o discurso de um "RH Estratégico" e práticas organizacionais. Em relação a seu papel, caberia ao $\mathrm{RH}$ (re-)pensar-se como função direcionada à promoção de organizações mais humanas.

Palavras-chave: RH Estratégico; Papeis e competências; Economias Periféricas.

\section{ABSTRACT}

The purpose of this article is to present results of a research aimed at investigating the roles and competencies required of Human Resources (HR) professionals in the reality of a peripheral economy country (Brazil). For such, a theoretical review was conducted, exploring the relationships between domestic and international studies into the HR function and the "competence" construct. In methodological terms, the research can be characterized as a case study, qualitative in nature, involving 32 interviews with presidents and directors of companies, as well as with Brazilian specialists in the area of people management. Findings unveiled unanimous understandings concerning the prevalence of people management models centered upon the "operating dimension", signaling discrepancies between the "Strategic HR" discourse and organizational practices. As far as its role is concerned, it behooves HR to (re)think itself as a function veered towards the promotion of more humane organizations.

Keywords: Strategic HR; Roles and Competences; Peripheral Economics.

1 Santos (2014) utiliza o conceito de "economia periférica" referindo-se aos países que não acompanham o desenvolvimento tecnológico e socioeconômico dos países desenvolvidos, como é o caso do Brasil. 


\section{INTRODUÇÃO}

As transformações tecnológicas, econômicas e mercadológicas que marcam o atual contexto de negócios, assim como a crescente ênfase nos "talentos e competências humanas" como fatores de diferenciação competitiva das organizações, têm pressionado a área de RH a rever a sua função na organização, demandando uma visão mais "estratégica" e "proativa" por parte de seus gestores e profissionais (BARTLETT; GHOSHAL, 1987; PRAHALAD; HAMEL, 1990). Nesse contexto, o RH depara-se com a incumbência de executar papeis diferenciados, muitas vezes mais complexos e mesmo paradoxais (ULRICH, 1998).

Assim, ao mesmo tempo em que o RH é convocado a realizar funções clássicas de agente "fiscalizador" e "legal", as forças competitivas sinalizam que é necessário a adoção de posturas mais estratégicas. Demandam, portanto, a ampliação de seu escopo de atuação, que além de atividades operacionais, devem incorporar uma postura mais "protagônica" no desafio de levar a organização a atrair, desenvolver e reter os talentos requeridos a um elevado padrão de competitividade (HARVEY, 1989; ULRICH, 1998).

Para fazer frente a esse escopo ampliado, pesquisas revelam a prevalência de discursos que preconizam "novos" papeis a serem desempenhados pelo $\mathrm{RH}$, bem como um amplo conjunto de competências a serem desenvolvidas por seus membros. Dentre os vários estudos que abordam tais construtos merece destaque contribuições de autores, tais como Ulrich (1998); Evans, Pucik e Barsoux (2002); Sarsur, Sant'Anna e Resende (2003); Lacombe e Tonelli (2001); Gubman (2004); Tanure, Evans e Cançado (2010); Tolfo e Piccinini (2011); Silva e Torres (2011), dentre outros.

A despeito da importância de um "RH Estratégico" no atual contexto de negócios, os estudos revelam que esse modelo não encontra respaldo no dia-a-dia da gestão das organizações brasileiras e que a área de $\mathrm{RH}$, ainda, centra-se em atividades operacionais. Em decorrência, questiona-se se os modelos de gestão de pessoas adotados pelas empresas brasileiras realmente evoluíram na direção de um "RH Estratégico" (CESAR; BIDO; SAAD, 2006). Nessa direção, Silva e Torres (2011) trazem à tona o seguinte questionamento: seria mais adequado falar de um movimento "reformista" da função RH, ou, por outro lado, de um processo de transformação que sustenta e legitima uma "nova" gestão de pessoas?

Tomando como referência esse quadro, o objetivo deste artigo é apresentar resultados de pesquisa direcionada a investigar, na realidade de um país de economia periférica (o Brasil), papeis e competências requeridos aos profissionais de $\mathrm{RH}$ no atual contexto de negócios. Como objetivos específicos buscou-se analisar, sob a ótica de principais "atores" envolvidos na condução de tais áreas (presidentes, vice-presidentes, diretores de RH e especialistas seniores da área): (1) o papel efetivamente desempenhado pela área de $\mathrm{RH}$; (2) os papeis que deveriam fazer parte do escopo de atuação do RH; (3) as competências requeridas aos gestores e profissionais da área; (4) antigos e novos dilemas enfrentados pelos profissionais de $\mathrm{RH}$.

No referencial teórico do artigo apresentam-se estudos internacionais e nacionais sobre a função RH - sob perspectiva sócio histórica - e de sua manifestação em organizações brasileiras. Discute-se, também, papeis e competências requeridas aos seus profissionais vis-à-vis desafios que enfrentam no exercício de suas funções no ambiente de negócios contemporâneo (ULRICH, 1998; SARSUR; SANT'ANNA; RESENDE, 2003; GUBMAN, 2004; TANURE; EVANS; CANÇADO, 2010).

Em termos metodológicos, a pesquisa que subsidiou os resultados deste estudo pode ser caracterizada como um estudo de natureza qualitativa, baseada na adoção do método de estudo de casos (YIN, 2005). A coleta de dados envolveu a realização de 32 entrevistas em profundidade com presidentes e diretores de empresas atuantes no Brasil, bem como com especialistas brasileiros na área de gestão de pessoas.

Em termos de sua relevância, o estudo revela-se significativo ao ampliar a literatura sobre a função "RH" na atualidade, analisando papeis e competências requeridas a seus profissionais, sob a perspectiva da cúpula estratégica das organizações, bem como de importantes formadores de opinião na área no Brasil. Finalmente, não se pode desconsiderar a relevância dos resultados do estudo no sentido de subsidiar o desenvolvimento de projetos de mudança na função RH nas organizações brasileiras que possa pronunciar um real caminho para a "modernidade" (TOURAINE, 
1993), ao considerar uma de suas dimensões centrais, porém, muitas vezes, ignorada: o elemento humano.

\section{REFERENCIAL TEÓRICO}

\subsection{Contextualizando a gestão de RH: do operacional ao estratégico?}

As pressões em torno da competitividade, os progressos tecnológicos, a globalização da economia e as mudanças nas condições mercadológicas, evidenciam a necessidade de as organizações revisitarem seus modelos de gestão, em particular as suas práticas e políticas direcionadas à gestão de seu capital intelectual (BARTLETT; GHOSHAL, 1987; PRAHALAD; HAMEL, 1990). Conforme salientam Prahalad e Hamel (1990), na medida em que fontes tradicionais de vantagem competitiva, tais como recursos tangíveis e mão-de-obra barata, não mais se revelam suficientes para proverem uma posição competitiva sustentável, os indivíduos e suas competências passam a ser enfatizados como elementos centrais de diferenciação estratégica. Sob essa perspectiva, a sustentabilidade das empresas depende cada vez mais da capacidade organizacional de desenvolver pessoas e criar políticas de RH que valorizem a dimensão humana.

A gestão de pessoas se apresenta, nesse quadro, como uma das áreas da organização mais sensíveis a variações ambientais e organizacionais . Exemplos dessa influência, além de fatores já mencionados, são impactos gerados pelas mudanças ocorridas na natureza do trabalho (TANURE, EVANS; CANÇADO, 2010; SILVA; TORRES, 2011). De acordo com Lacombe e Tonelli (2001), os tradicionais contratos firmados entre trabalhador e empresa, que previam uma relação duradoura, são apresentados como obsoletos, face à flexibilização das relações de trabalho e à emergência de novas formas de se trabalhar. Ademais, fatores organizacionais como a racionalização e a automatização de funções, a sofisticação dos mecanismos de controle, assim como o aumento da pressão sobre os trabalhadores, incluindo-se aquela por contínua atualização profissional, tem produzido efeitos decisivos nas políticas e práticas de RH (STOREY, 1995).
Se, por um lado, tais transformações trazem à tona a importância de as organizações adotarem modelos de RH mais "estratégicos"; por outro, estudos revelam que as práticas de gestão de pessoas de empresas brasileiras encontram-se "defasadas", a despeito de discursos de "modernização" amplamente disseminados no contexto corporativo (TANURE; EVANS; CANÇADO, 2010). Ademais, evidencia-se, no Brasil, o desenvolvimento de áreas de $\mathrm{RH}$ com quase meio século de atraso em relação a processos vivenciados nos países desenvolvidos (TANURE; EVANS; CANÇADO, 2010). No país, mesmo com a implantação de plantas industriais modernas, a partir do século XX, a função RH parece limitar-se às atividades rotineiras, como o controle de frequência de funcionários e o processamento da folha de pagamento.

Analisando o papel histórico do $\mathrm{RH}$ no contexto Brasil, observa-se que o fortalecimento do movimento sindical e a criação de leis destinadas a regulamentar as relações trabalhistas, na década de 1930, resultaram em importantes modificações nas condições de trabalho. Nesse contexto, assiste-se à implantação dos primeiros "Departamentos de Pessoal" em empresas brasileiras (SARSUR; SANT'ANNA; RESENDE, 2003; CANÇADO et al., 2005). Decisivo, nesse estágio, foi o estabelecimento da "Consolidação das Leis do Trabalho - CLT”, em 1943, legislação que ainda hoje regula as relações de trabalho no país. A despeito desse significativo passo, o principal papel da área de pessoal, ainda, consistia na adoção de medidas destinadas a assegurar o cumprimento da lei, conferindo ao setor caráter eminentemente "funcional-legal".

Com o intuito de modificar tal situação, são criados, a partir dos anos 1970, movimentos orientados a imprimir à gestão de $\mathrm{RH}$ traços menos "burocráticos" (CANÇADO et al., 2005). Assim, a década de 1980 se vê marcada por esforços para a inclusão de políticas e práticas voltadas para ampliar a produtividade e o comprometimento do trabalhador no ambiente de trabalho, a partir da adoção de sistemas de benefícios e de ações para a melhoria do clima organizacional. A despeito desta evolução, as atividades realizadas 
pelo $\mathrm{RH}$ ainda eram caracterizadas por uma abordagem operacional, embora de formato mais processual. (GUBMAN, 2004).

Com a intensificação da abertura do mercado brasileiro, na década de 1990, as organizações buscam desenvolver práticas de gestão de $\mathrm{RH}$ mais "modernas", se baseando, sobretudo, em modelos concebidos em outros países, como o Japão e os Estados Unidos (TANURE; EVANS; CANÇADO, 2010). Tais assimilações, não raro, sem devidas adequações às especificidades do contexto nacional e, em decorrência, desconexas com a realidade local, colocando-se em questionamento a contribuição do $\mathrm{RH}$ para o negócio das empresas (CASTRO; KILIMNIK; SANT'ANNA, 2008; LACOMBE, 2006).

Muito embora se possa falar em alguns "avanços", pesquisadores indicam que a função RH não se transformou efetivamente, mantendo-se no paradigma tradicional focado na regulação legal da força de trabalho (GUBMAN, 2004; SILVA; TORRES, 2011). No máximo, teriam se sofisticado ao introduzir abordagens mais orientadas à ampliação do comprometimento dos indivíduos com o trabalho e com os resultados, incorporando, para tal, estratégias mais aderentes ao contexto e às competências por ele requeridas para o desempenho dos negócios.

$\mathrm{Na}$ atualidade, assiste-se tentativas de um $\mathrm{RH}$ que busca alinhar as suas estratégias aos objetivos corporativos com a finalidade de evidenciar o papel do setor de Recursos Humanos no desempenho do negócio (GUBMAN, 2004; SILVA; TORRES, 2011). Essa "nova" abordagem baseia-se nas noções de uma gestão de pessoas conectada à estratégia das organizações, orientada para resultados e que busca oferecer contextos internos que possibilitem aos indivíduos aplicar as suas competências no trabalho. Diversos autores denominam essa fase de "RH Estratégico" ou de "Gestão Estratégica de RH” (MINER; CRANE, 1995; ALBUQUERQUE, 1999; SARSUR; SANT'ANNA; RESENDE, 2003; CANÇADO et al., 2005). Consequentemente, registram-se movimentos de alteração da nomenclatura atribuída à área, objetivando deslocá-la dos significantes "Departamento de Pessoal" ou "Departamento de RH" para outros, mais "humanizados", como "Gestão do Capital Humano", "Gestão de Pessoas", "Gestão de Gente" ou "Gestão de Talentos".

Nessa direção, o estudo de Carrig e Wright (2006) evidencia que as práticas de RH deveriam ser caracterizadas como "transformacionais", em contraposição às "transacionais" (que se limitam às atividades operacionais da função $\mathrm{RH}$ ) e às "tradicionais" (que abrangem as práticas convencionais do $\mathrm{RH}$, como as de recrutamento e seleção e avaliação de desempenho). As práticas "transformacionais", por sua vez, consideradas de natureza mais "estratégica", se fundamental na conexão das atividades de RH aos objetivos organizacionais por meio da inclusão de metas de gestão de pessoas no planejamento estratégico da empresa.

A despeito do discurso de um "RH Estratégico" bastante disseminado no ambiente acadêmico e empresarial, pesquisas na área têm sugerido que tal modelo não encontra respaldo no dia-a-dia de empresas brasileiras (CANÇADO et al., 2005; SARSUR; SANT'ANNA; RESENDE, 2003; CESAR; BIDO; SAAD, 2006; SILVA; TORRES, 2011). Ou seja, o modelo de RH dessas organizações ainda está longe de colocar a dimensão humana como ponto central das estratégias organizacionais. Sob essa perspectiva, Cançado et al. (2005, p. 4) afirma que as políticas de RH “(...) representam ainda as antigas proposições, sob nova roupagem, o que demonstra o reduzido avanço do humanismo praticado pelas empresas". Portanto, não seria mais apropriado se falar, no máximo, em "reforma" da função RH, sem lastros de uma real transformação em seus fundamentos e estrutura? Cesar, Bido, Saad (2006) e Silva e Torres (2011) defendem esse argumento. Para eles o que predomina é, de fato, um discurso sobre uma "nova" gestão de pessoas que não encontra respaldo nas práticas das empresas brasileiras. Como resultado, segundo esses autores, o RH não teria efetuado o salto qualitativo que lhe possibilitaria uma atuação estratégica.

Procedida à contextualização da função RH, na próxima seção é apresentada a revisão teórica sobre os papeis e competências requeridas a seus profissionais. 


\subsection{Papeis e competências do "novo" RH}

Face às transformações discutidas na seção anterior, cabe ao RH contemporâneo ampliar o seu escopo de atuação, superando a ênfase em atividades "operacionais" e assumindo papel mais "protagônico" no processo de desenvolvimento, valorização e retenção de pessoas. Como consequência, o RH depara-se com um amplo repertorio de papeis a serem desempenhados, dentre eles, participar mais diretamente da elaboração das estratégias empresariais, ser o principal agente entre as pessoas e a direção da organização e cuidar da cultura organizacional (CANÇADO et al., 2005).

Segundo Cesar, Bido, Saad (2006), os profissionais de RH deveriam, ainda, assumir papel de "consultores" ou "coaches" da gestão, funcionando como parceiros do presidente, dos gestores e dos colaboradores, fomentando contextos favoráveis para que as pessoas coloquem em prática suas competências.

Um dos modelos teóricos no qual se aborda a função RH é o Ulrich (1998), denominado de múltiplos papeis do RH. Segundo o autor, os profissionais de $\mathrm{RH}$ devem exercer diferentes papeis, classificados em:

Figura 1 Múltiplos Papeis do RH

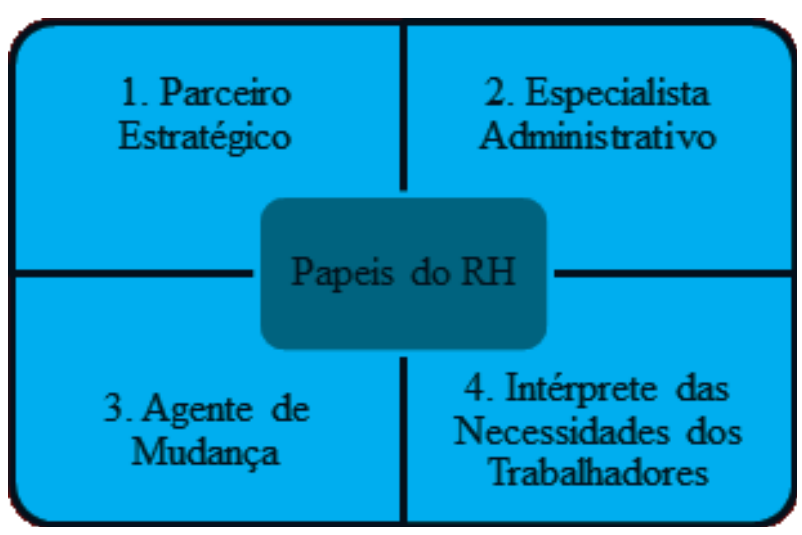

Fonte: Elaborado pelos autores

Como "Parceiro Estratégico", compete ao RH definir práticas de gestão de pessoas que contribuam para os objetivos estratégicos da organização. Pressupõe-se, nessa direção, alinhamento entre as políticas de $\mathrm{RH}$ e as estratégias do negócio. Por outro lado, o papel do RH como "Especialista Administrativo" pressupõe a realização das atividades rotineiras relacionadas a $\mathrm{RH}$, tais como processos de admissão e rescisão, recrutamento e seleção, treinamento e avaliação de desempenho (ULRICH, 1998).

Ao RH enquanto "Agente de Mudança" compete, por sua vez, o papel de preparar o contexto cultural para que as transformações necessárias se processem na organização. Nesse escopo é fundamental o desenvolvimento de ações de sensibilização, preparação e capacitação das pessoas para fazerem frente ao novo cenário. Por fim, como "Intérprete das Necessidades dos Trabalhadores", o RH deve desenvolver ações voltadas para ampliar o comprometimento dos funcionários, seja estabelecendo canais de interlocução com as pessoas, seja criando contextos organizacionais favoráveis à aprendizagem e à aplicação das competências dos indivíduos no trabalho.

Outro modelo teórico que aborda os papeis de RH é o de Evans, Pucik, Barsoux (2002), revisitado por Tanure, Evans e Pucik (2007) e Tanure, Evans, Cançado (2010). A partir de pesquisas realizadas em empresas europeias e norte-americanas, Evans, Pucik, Barsoux (2002) verificaram que a gestão de RH assume diferentes "faces" ou "perspectivas", que podem ser evidenciadas a partir de três dimensões: Navegador, Parceiro de Mudança e Construtor.

Na dimensão "Construtor", os autores propõem uma integração das práticas de RH com as demais funções da empresa (Finanças, Marketing, Operações, Logística, etc.). Trata-se, em linhas gerais, de perspectiva orientada para o interior da empresa. Na segunda "face" - "Parceiro de Mudança" - o RH busca contribuir com estratégias de gestão de pessoas que possibilitem à organização melhor se adaptar ao ambiente externo. Assim, o RH deve envolver os gerentes de linha responsáveis pela execução das mudanças internas necessárias a cada "nova" estratégia. Por fim, o RH como "Navegador" deve desenvolver ações relacionadas à gestão de pessoas que estejam conectadas à estratégia corporativa da organização. Por meio de ações decisivas (tais como, capacitação, valorização, reconhecimento), o RH pode contribuir para a criação de contextos organizacionais que permitam aos indivíduos aplicar as suas competências no exercício de suas funções, contribuindo para que a organização lide mais efetivamente com ambiguidades e incertezas (EVANS; PUCIK; BARSOUX, 2002).

O modelo de Evans, Pucik, Barsoux (2002), foi, todavia, concebido com base em pesquisas desen- 
volvidas em contextos europeu e norte americano, não captando, portanto, a realidade brasileira. Nesse sentido, Tanure, Evans, Pucik (2007), após revisão da literatura nacional, identificaram outra "face" do RH, denominada de "Executor". Os autores argumentam que a inclusão de tal dimensão no modelo inicial é importante para a sua adequação ao contexto brasileiro, pois diversas empresas no país possuem um $\mathrm{RH}$ executor, que se restringe ao exercício de funções operacionais, sendo seu papel predominantemente "legal" e "fiscalizador". Finalmente, os autores salientam que as quatro "faces" do RH podem ser caracterizadas como um processo, sendo a "face executor" o estágio inicial e o "navegador" o estágio mais avançado.

Considerando-se os papeis que o $\mathrm{RH}$ tem sido demandado a desempenhar, emerge a seguinte questão: que competências passam a ser requeridas aos profissionais da área? Do ponto de vista teórico, ressalta-se que o construto Competência não é recente, tendo sido amplamente discutido por diversos pesquisadores desde a década de 1980. A despeito das várias contribuições teóricas não há consenso acerca de sua definição (BOYATZIS, 1982; SPENCER; SPENCER, 1993).

Para Sant'Anna, Moraes e Kilimnik (2005), apesar das diferentes abordagens, alguns pontos comuns podem ser identificados. Em primeiro lugar, a competência é comumente apresentada como um conjunto de características ou requisitos - saberes, conhecimentos, aptidões, habilidades - indicado como condição capaz de produzir resultados esperados (BOYATZIS, 1982; SPENCER; SPENCER, 1993). Outro ponto comum é a conformidade desse conceito com o discurso empresarial vigente, bem como com as demandas advindas dos processos de reestruturação e de modernização produtiva em voga (STROOBANTS, 1997).

Uma definição amplamente utilizada nos estudos sobre competência é a de Stroobants (1997) que a define como resultante de três componentes: Saberes ou conhecimentos formais, que podem ser traduzidos em fatos e regras; Saber-fazer, que pertence à esfera dos procedimentos empíricos, como os conhecimentos tácitos que se desenvolvem na prática do trabalho; e Saber-ser, entendido como o saber social, incluindo interpretações e visões do mundo. Kilimnik et al. (2004) acrescentam que as competências são contingenciais, na medida em que são desenvolvidas e exercidas em contextos específicos.

De modo geral, algumas competências têm sido mais demandadas no contexto de negócios contemporâneos que, segundo Sant'Anna, Moraes e Kilimnik (2005), tratam-se de conhecimentos, habilidades e atitudes mais abrangentes que aquelas requeridas em etapas anteriores do desenvolvimento do capitalismo. $\mathrm{O}$ autor acrescenta que, tendo em vista a valorização da inovação e da flexibilidade, tem-se enfatizado mais amplamente competências interativas, comunicativas, sociais e comportamentais, incluindo "virtudes" como paciência, tolerância, predisposição para apreender a perspectiva do outro e compreender suas atitudes. Além desses "atributos", deve-se mencionar a disposição para aceitar e integrar as mudanças.

Nessa direção, de acordo com Steffen (1999), dentre as competências mais valorizados no contexto atual, encontram-se as competências cognitivas, relacionais, emocionais e de liderança, superando a ênfase no domínio de competências técnicas, típicas da noção de qualificação (saber-fazer). Em nível gerencial, Barlett e Ghoshal (1997) identificam três tipos de competências relevantes: características da personalidade (relacionadas ao caráter do indivíduo), conhecimentos (adquiridos por treinamento no decorrer da carreira) e habilidades especializadas (decorrentes da função desempenhada pelo indivíduo).

Em relação às competências específicas do profissional de RH, Silva e Torres (2011) defendem que ele deve entender do negócio da empresa, além das práticas e ferramentas específicas da área de $\mathrm{RH}$. Além disso, os autores sugerem que esse profissional deve ser capaz de preparar as pessoas para processos de mudança organizacional e de contribuir para a criação de ambientes de trabalho favoráveis ao desenvolvimento de capacidades individuais.

Lacombe e Tonelli (2001) e Cançado et al. (2005) sugerem que o gestor de RH deve assumir o papel de "consultor", no sentido de apoiar as demandas dos demais setores da empresa no que se refere à assuntos de gestão das pessoas, realizando, concomitantemente, conexões entre essas áreas. Para tanto, “(...) o perfil do profissional inclui um conhecimento global, atenção com os resultados finais da organização, trabalho em parceria com as outras áreas, além de contínuo autodesenvolvimento". (CANÇADO et al., 2005, p. 3). 
Nessa direção, pesquisas na área têm enfatizado a importância do desenvolvimento, pelos profissionais de $\mathrm{RH}$, de competências mais abrangentes e vinculadas ao negócio da organização (e não somente as habilidades específicas da função RH) (LACOMBE; TONELLI, 2001; SILVA; TORRES, 2011). Tais resultados podem ser reflexo do papel "funcional" clássico que o RH tem executado nas empresas brasileiras nas últimas décadas, sinalizando que a área deve repensar seu escopo de atuação.

Feita a contextualização teórica, a próxima seção contempla os aspectos metodológicos da pesquisa.

\section{METODOLOGIA}

Em termos metodológicos, a pesquisa que gerou os resultados apresentados neste artigo pode ser caracterizada como um estudo de campo de natureza qualitativa, conduzida por meio do método de estudo de caso. Tal método consiste na análise exaustiva de objetos empíricos, sejam eles situações, pessoas ou organizações, bem como a natureza dos fenômenos que os compõem (EISENHARDT, 1989; YIN, 2005). É indicado quando o fenômeno em estudo é complexo, contemporâneo e insere-se num contexto real, como é o caso da presente pesquisa que investigou os papeis e as competências requeridas aos profissionais de RH no atual contexto dos negócios.

Outra vantagem da adoção de pesquisa qualitativa é que a mesma contribui para o entendimento holístico do problema estudado, bem como possibilita a análise do impacto das variáveis contextuais na ocorrência do fenômeno (YIN, 2005). O estudo de casos, por sua vez, possibilita ao investigador identificar fatores que estimulam a ocorrência de um evento, bem como compreender a interação que se estabelece entre tais variáveis. Assim, se torna possível visualizar o caso pesquisado como uma rede de inter-relações na complexidade em que ela se apresenta (GREENWOOD, 1973; BONOMA, 1985).

A escolha do(s) caso(s) em pesquisa qualitativa constitui, todavia, decisão crucial, na medida em que tem implicações na relevância dos resultados do estudo. Tal escolha, portanto, não pode ser aleatória, mas sim intencional, orientada para a riqueza com que o fenômeno se apresenta (EISENHARDT, 1989;
YIN, 2005). Como a intenção foi captar e comparar diferentes visões sobre os papeis e competências do $\mathrm{RH}$, foram considerados os seguintes atores como sujeitos entrevistados da pesquisa (ver Tabela 1):

Tabela 1 Relação de Entrevistados

\begin{tabular}{l|c}
\multicolumn{1}{c|}{ Sujeitos Entrevistados } & Quantidade \\
\hline Presidentes de empresas & 07 \\
\hline Vice-presidentes e Diretores de RH & 12 \\
\hline Especialistas na área de Gestão de Pessoas & 13 \\
\hline Total & $\mathbf{3 2}$ \\
\hline
\end{tabular}

Fonte: Elaborado pelos autores.

No que tange ao primeiro grupo de entrevistados foi realizado um total de 07 (sete) entrevistas com os principais executivos de empresas nacionais e multinacionais atuantes no Brasil, vinculadas aos seguintes setores: farmacêutico, cosméticos, educação, telecomunicações, consultoria e público. Em relação aos executivos de $\mathrm{RH}$ foram contemplados 12 (doze) ocupantes de cargos da alta adminsistração (Vice-presidentes e Diretores de RH) de organizações de grande porte atuantes no país. Observa-se, também, diversidade dos segmentos de atuação de suas empresas, sendo duas do setor financeiro, duas do setor automotivo e as demais dos setores de saúde, comunicação, construção civil e siderurgia. A maior parte dos executivos possui mais de vinte anos de experiência na área. Por fim, o terceiro grupo de entrevistados foi formado por 13 (treze) especialistas, identificados por seus conhecimentos, reputação e experiência em temas vinculados à gestão de pessoas. Mais especificamente, foram selecionados 07 (sete) professores de instituições brasileiras de ensino superior, 04 (quatro) consultores e 02 (dois) ligados à universidades corporativas.

Por considerar a percepção de três grupos de respondentes (presidentes versus diretores versus especialistas), foi possível comparar os achados obtidos a partir da visão de cada grupo de entrevistados, bem como revelar padrões de casos e contradições entre eles.

Em relação ao instrumento de coleta de dados, foi utilizado um roteiro de entrevista semiestruturada. Dentre as principais categorias exploradas 
nas entrevistas merecem destaque: a função RH nas organizações brasileiras sob uma perspectiva sócio histórica; papeis e frentes de atuação dos gestores e profissionais da área; competências requeridas a seus profissionais e desafios por eles enfrentados para a adoção de um modelo de "RH Estratégico".

Para o tratamento dos dados coletados foi utilizado o método de análise de conteúdo por categoria (RICHARDSON, 1985; FLICK, 2009). Essa metodologia consiste no uso de técnicas de sistematização, interpretação e descrição do conteúdo das informações coletadas, a fim de compreender melhor o discurso, aprofundar suas características e extrair os detalhes relevantes. Como resultado foi possível examinar várias dimensões dos relatos dos entrevistados e construir inferências a partir deles. Para facilitar essa etapa foram criadas categorias de análise com base na literatura e revisadas à luz das evidências da pesquisa (EISENHARDT, 1989).

Como auxílio à análise dos dados empíricos, foi utilizado o software de tratamento qualitativo $\mathrm{N}$-vivo 9.0, seguindo-se passo-a-passo os processos de codificação e categorização, conforme indicados por Flick (2009). Desse modo, buscou-se, primeiramente, a geração exaustiva de categorias representadas por um conjunto de códigos referentes a diversas impressões e percepções sobre o tema em estudo (GIOIA; THOMAS, 1996), resultando nas seguintes categorias: "Papeis da área de RH", "Novos papeis requeridos ao RH e seus profissionais", "Competências individuais requeridas aos profissionais de RH", conforme apresentados na seção subsequente.

\section{APRESENTAÇÃO E ANÁLISE DOS DADOS}

\subsection{Papeis da área de RH}

Os achados empíricos revelam percepções unânimes dos respondentes quanto a um modelo de $\mathrm{RH}$ tradicional e que executa, predominantemente, atividades operacionais em uma lógica de curto prazo, reforçando achados apontados por estudos brasileiros (CESAR; BIDO; SAAD, 2006; SILVA; TORRES, 2011). Os entrevistados revelam, ainda, que a área de RH desenvolve poucas iniciativas "sistêmicas" e de "longo prazo", conforme tangenciam os relatos de um Especialista e de um Presidente entrevistados:

\begin{abstract}
O pessoal do RH é muito atento aos formalismos. Que é um pedaço importante. A gente não pode deixar de fazer folha de pagamento bem-feita, você deve ter um plano de cargos e salários, na questão das legislações. Mas isso é mecânico. (...). O que é estratégico é, efetivamente, cuidar da cultura da organização, porque dependendo do clima que você tem na organização, você é mais ou menos produtivo (Entrevista Especialista 3).

As áreas de RH não se livraram do estilo e nem dos paradigmas do passado na forma de poder colaborar com a empresa. Ainda estão muito atreladas a vícios de ferramentas e modismos. $\mathrm{E}$ eu vejo muito pouco, a área de RH fazer a diferença para construir um ambiente de aprendizado (Entrevista Presidente 3).
\end{abstract}

Comparando tais resultados com os modelos teóricos de Ulrich (1998) e de Tanure, Evans e Cançado (2010) verifica-se a predominância da função do RH como "Especialista Administrativo" e "Executor".

Os dados revelam, também, que os entrevistados reconhecem que compete ao $\mathrm{RH}$ executar essas tarefas operacionais relacionadas a recursos humanos. Todavia, enfatizam que a área dever ampliar seu escopo de atuação incluindo atividades mais "estratégicas", como fortalecer a cultura organizacional, participar mais ativamente do planejamento estratégico da empresa e criar um ambiente interno que permita às pessoas aplicar as suas competências, bem como aprimora-las.

Ao mesmo tempo, os achados empíricos denotam percepções quanto à fraca integração entre as diversas atividades (ou subáreas) do RH, dificultando a criação de um conceito sistêmico de gestão de pessoas nas empresas. O esforço de maior conexão entre seus processos internos, sinalizado por Cançado et al. (2005), não tem sido alcançado pelos profissionais da área, conforme ilustra o relato abaixo:

\footnotetext{
E a gente diagnosticou que não conseguimos ter em RH indicadores de RH estratégicos, que deem um mapa de como está a organização do ponto de vista de pessoas. Tem-se muita informação picada, sem ter uma análise geral do que isso significa (Entrevista Presidente 7).
}

Uma questão que emergiu nas entrevistas com o grupo de especialistas é a percepção de que o RH "copiou" o modelo de funcionamento de outros setores, passando a atuar com ênfase no resultado financeiro 
do negócio, desconsiderando os impactos que essa atuação poderia gerar nas práticas e políticas de gestão de pessoas. Assim, na percepção dos especialistas, o RH se afastou do papel que efetivamente deveria exercer, conforme tangencia esse relato: "O $\mathrm{RH} n a$ verdade aprendeu o discurso do negócio e esqueceu o discurso das pessoas" (Entrevista Especialista 11).

Entende-se, ademais, que o RH adotou tal postura "visando se legitimar perante a organização", haja vista ser comum a seus profissionais sentirem-se "fora das prioridades e das estratégias organizacionais. Nessa linha, processos de negação ou de racionalização de seu papel [na perspectiva psicanalítica] daria conta de que o RH seguiria a lógica de funcionamento do sistema para que seus projetos sejam aceitos na organização:

$\mathrm{O}$ que eu acho que o $\mathrm{RH}$ precisa destruir? O seu complexo de inferioridade. Então, a primeira coisa para ele ser um melhor líder de RH, ele precisa se achar 'capaz de'. Capaz de enfrentar o CEO, capaz de enfrentar os seus pares, capaz de enfrentar a sua equipe, capaz de aumentar a relevância estratégica do $\mathrm{RH}$ dentro das decisões da empresa (Entrevista Presidente 6).

Não obstante, os diretores de RH entrevistados justificam que tal "sentimento de inferioridade" decorre de um papel secundário que a área assume em algumas empresas brasileiras, como sugere esse relato: "Enfim, todas aquelas coisas que ninguém quer, acabam caindo aqui no RH” (Entrevista, Diretor 3). Por fim, há percepções de que a importância do RH na empresa depende do valor que o presidente atribui a essa função. Ou seja, se o executivo principal não trata o RH como parceiro estratégico, o papel do setor tende a ficar limitado. Especialistas entrevistados, também, corroboram tal situação: "Se o RH não estiver subordinado diretamente ao presidente, ele não tem condições de ser estratégico. Cada presidente tem o RH que merece" (Entrevista Especialista 3). Por outro lado, alguns especialistas advertem quanto à falta de postura proativa da área de $\mathrm{RH}$, no sentido de defender as suas causas e demostrar o real valor dos projetos de gestão de pessoas.

Nessa direção, diversos entrevistados, nos três grupamentos, revelam que é necessária uma mudança de postura por parte dos profissionais de $\mathrm{RH}$ para que a área assuma essa posição mais "estratégica”. Assim, o RH deveria ampliar o seu escopo de atuação e alinha-lo aos objetivos corporativos para que a área possa ser mais reconhecida e valorizada, conforme corrobora o especialista:

A área de gestão de pessoas, primeiro, tem que conseguir se incluir na alta gestão da empresa. Segundo, para ela conseguir isso ela tem que se fazer respeitar, para ela se fazer respeitar ela tem que saber o que ela está falando e fazendo (Entrevista Especialista 5).

Em suma, se por um lado, a organização pode limitar a atuação do RH como parceiro estratégico (pela estrutura formal ou por opção do presidente), por outro, é necessário um RH mais ousado e articulado, de mindset sistêmico e mais antenado às questões contemporâneas que competem ao setor.

\section{2 “Novos" papeis requeridos ao RH e seus profissionais}

Os presidentes, diretores e especialistas entrevistados apontam diversos papeis que deveriam fazer parte do escopo de atuação do $\mathrm{RH}$ das empresas brasileiras (ver Figura 2). Nessa direção, os dados relevam certo consenso em relação aos "novos" papeis a serem desenvolvidos pelo $\mathrm{RH}$.

Figura 2 Novos papeis do $\mathrm{RH}$

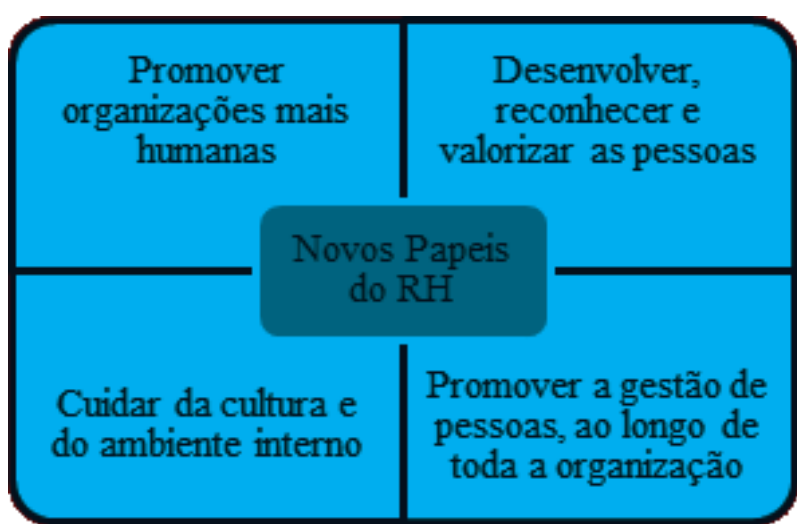

Fonte: Elaborado pelos autores

Um aspecto recorrentemente citado nas entrevistas é a necessidade de uma atuação mais proativa do RH na promoção de uma organização mais humana e orientada para pessoas. Embora afirmativas como "a organização existe por causa das pessoas" e "as pessoas não são mais um recurso à disposição da empresa" possam parecer óbvias, os entrevistados 
apontam que, na prática, aumentam as pressões e o nível de controle sobre os trabalhadores, conforme discutido por Storey (1995).

No Brasil, a situação parece não diferir das organizações investigadas por esse autor. O RH das empresas brasileiras, na percepção da maioria dos entrevistados, não coloca a dimensão humana no centro de suas ações, prevalecendo um modelo de gestão de pessoas "operacional e burocrático". Assim, caberia ao RH rever as suas políticas e práticas no sentido de humanizar o ambiente organizacional, conforme corrobora o seguinte relato:

O presidente recém-admitido foi interpelado pela imprensa e falou assim: "Qual é o seu grande objetivo como presidente dessa empresa?” E ele virou e falou assim: "Humanizá-la!" Uma boa fala! Por quê? Naturalmente porque ele viu que a linha do que estava sendo conduzido é desumana (Entrevista Especialista 5).

Outra importante frente de atuação do $\mathrm{RH}$, sugerida pelos diretores de $\mathrm{RH}$ e especialistas entrevistados, está vinculada ao papel do $\mathrm{RH}$ na promoção de um ambiente organizacional que favoreça o desenvolvimento técnico e comportamental dos colaboradores (abrangendo iniciativas de suporte, capacitação e reconhecimento das pessoas) e que permita aos indivíduos aplicarem as suas competências. Os relatos revelam que tais questões se encontram, também, dentre as principais preocupações dos presidentes entrevistados, os quais sinalizam que o $\mathrm{RH}$ deve ser capaz de responder questões do tipo: "Como desenvolver, reter e valorizar as pessoas?" ou "Considerando-se os objetivos da empresa, quais competências são necessárias?"

Constata-se, igualmente, amplo número de relatos que destacam a relevância do papel do $\mathrm{RH}$ junto à dimensão da "cultura organizacional", seja apoiando na disseminação das diretrizes da cúpula nas diferentes instâncias organizacionais, seja repassando as necessidades dos funcionários ao presidente, seja desenvolvendo ações para fortalecer a cultura interna, conforme prenuncia estudo de Cançado et al. (2005).

Outra frente de atuação do $\mathrm{RH}$, indicada pelos três grupos de entrevistados, está relacionada à promoção de ações de gestão de pessoas ao longo de toda a organização. Como os gestores das diversas áreas da empresa lidam com questões vinculadas à gestão de pessoas, espera-se que o $\mathrm{RH}$ atue como parceiro dos setores, criando relações de confiança e fornecendo a assessoria necessária para a gestão de pessoas ao longo da organização, função que Cesar, Bido e Saad (2006) denominam de "consultores de gestão".

Dentre as responsabilidades do $\mathrm{RH}$, o grupo de presidentes, especificamente, enfatizou que o diretor da área deve apoiar a elaboração do planejamento estratégico da empresa definindo as prioridades em termos de gestão de pessoas, bem como deve assumir uma função de representante dos funcionários perante o presidente (CANÇADO et al., 2005). Em outros termos: "O RH tem esse papel de trazer a voz do povo para o top management da organização. Mas, por outro lado, também tem obrigação de trazer, para essa base da organização, as seguintes direções: quais são as estratégias?" (Entrevista Presidente 6).

Finalmente, vale reiterar a relevância atribuída à função do RH como "facilitador das mudanças organizacionais" mencionada pelos diretores entrevistados, cabendo à área colocar-se como o principal interlocutor de questões da cultura organizacional e, ao mesmo tempo, fornecer suporte aos demais setores da organização nesse processo.

\subsection{Competências requeridas aos profissionais de $\mathrm{RH}$}

Para fazer frente aos papeis requeridos a esse "novo" RH, os entrevistados recomendam o desenvolvimento de competências pelos profissionais da área, as quais foram agrupadas em três categorias (ver Figura 3):

Figura 3 Competências requeridas ao "novo" RH

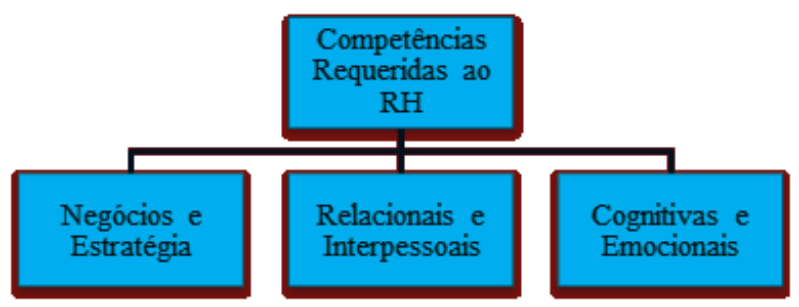

Fonte: Elaborada pelos autores.

A competência de "Negócios e Estratégia" está relacionada a conhecimentos "mais abrangentes", os quais foram subdivididos em duas subcategorias: 
(1) visão estratégica do negócio: orientação para resultados; alinhamento do $\mathrm{RH}$ com a estratégia; compreensão do ambiente externo e do setor de atuação da empresa; (2) visão sistêmica do ambiente interno: leitura sistêmica da empresa permitindo uma compreensão das partes, de suas conexões e do sistema, como um todo.

Tais achados reforçam argumentos de estudos anteriores que sinalizam a importância de os gestores de RH desenvolverem competências vinculadas ao negócio da organização e que lhes permitam visão mais sistêmica da empresa (LACOMBE; TONELLI, 2001; SILVA; TORRES, 2011). Não obstante, a maioria dos entrevistados entende que o $\mathrm{RH}$ ainda tem atuado com ênfase no ambiente interno, descuidando de variáveis ambientais que interferem no funcionamento da empresa, conforme sugere o relato: “O meu segundo parêntese é que gerir pessoas é gerir pessoas numa empresa, logo em um contexto, você tem que ter conhecimento do negócio" (Entrevista Especialista 5). No entanto,

Para você conseguir dar esse impacto você tem que entender dos fundamentos da indústria. Então não é só uma leitura de gente, você tem que ter uma leitura de 'business' e conseguir fazer a integração das duas (Entrevista Diretor 8).

Todavia, em decorrência da pressão por alinhar o RH ao negócio, parte dos entrevistados salienta que o setor passou a enfatizar os resultados da empresa, "esquecendo-se das pessoas". Assim, o profissional de RH depara-se com o dilema de como equilibrar ações que contribuam para os resultados do negócio cuidando ao mesmo tempo da dimensão humana da empresa.

O segundo grupo de competências necessárias ao gestor de RH - "Relacional e Interpessoal" - inclui a capacidade de mobilizar, articular e influenciar pessoas; achados convergentes com o estudo de Sant'Anna (2002). Começando por valorizar a dimensão humana, os entrevistados ressaltam a importância do carisma, da comunicação e da capacidade de estabelecer relações de confiança. Como o RH se articula com todos os setores da organização, o profissional da área deve estar preparado para sustentar ideias, gerar confiança e mobilizar pessoas, conforme evidencia o relato abaixo:
O executivo de $\mathrm{RH}$ precisa ser um absoluto articulado, porque ele tem que permear por toda a organização. Ou seja, ele tem que sentar com a produção, marketing, finanças. Precisa ter carisma. Porque ele não vai conseguir influenciar ninguém. A liderança dele precisa ser por adesão, por espontaneidade (Entrevista Especialista 3).

Finalmente, o terceiro grupo de competências emergente nos dados empíricos refere-se à habilidade dos profissionais de $\mathrm{RH}$ em lidar com pessoas, o que implica no desenvolvimento de capacidades emocionais e cognitivas. Inclui-se nesse grupo aspectos como sensibilidade e habilidade de ouvir e entender o outro, conforme tangencia o relato abaixo:

\footnotetext{
Tem que ter sensibilidade. Ele não pode ficar preso nos sistemas, ele tem que ser um pensador, um transformador, ele tem que fazer uma boa leitura de ambiência, uma boa leitura de cultura. Isso o que você está falando são competências que são de lidar com o humano, o aspecto intangível (Entrevista Especialista 1).
}

Além das competências que foram consenso entre os três grupos de entrevistados, merece destaque relatos de diretores que enfatizam a importância de os profissionais da área deterem conhecimentos específicos da função RH. Em outros termos, os profissionais devem "ter domínio das atividades, práticas e ferramentais específicos da área de RH" (Entrevista, Diretor 8). Finalmente, os presidentes sugerem que os gestores da área devem desenvolver habilidade para lidar com ambiguidades e incertezas, no sentido de estarem aptos a preparar a organização para processos de mudança, como analisado por Sant’Anna, Moraes e Kilimnik (2005).

\section{CONCLUSÕES}

Cabe-nos, a priori, retornar à questão central deste artigo: qual o papel do RH e que competências são requeridas a seus profissionais com vistas a atuarem com maior efetividade no contexto contemporâneo de negócios? Resultados da pesquisa empírica revelam, de início, significativa convergência entre as percepções dos três grupos de entrevistados. Desvelam, nessa direção, percepções unânimes quanto ao modelo de RH ainda marcado pela adoção de "instrumentos tradicionais", com ênfase em "atividades 
operacionais" e pela "perspectiva de curto prazo". Nessa direção, tomando como base os modelos de papeis de $\mathrm{RH}$ discutidos na revisão teórica verifica-se que a gestão de RH pode ser classificada como mais afim ao tipo "Executora" (TANURE; EVANS; CANÇADO, 2010) e seus profissionais como "Especialistas Administrativos" (ULRICH, 1998).

Evidentemente, os entrevistados consideram existir tarefas operacionais que são de responsabilidade do RH, todavia, advertem que a área deveria ampliar seu escopo de atuação, incluindo atividades mais estratégicas, como promover iniciativas de desenvolvimento das pessoas e cuidar do ambiente institucional.

Tais resultados corroboram estudos anteriores que revelam que não há consonância entre o discurso contemporâneo de um "RH Estratégico" e as práticas efetivamente realizadas pela área nas empresas brasileiras. Assim, questiona-se a contribuição do RH para o desempenho das organizações, bem como se as políticas de gestão de pessoas evoluíram do operacional ao estratégico (CANÇADO et al., 2005; CESAR; BIDO; SAAD, 2006).

Sob a ótica dos três grupos de entrevistados, a área de RH deveria incluir em sua agenda questões como a promoção de organizações mais humanas, mais estímulos ao desenvolvimento e à valorização das pessoas e maior cuidado com a cultura organizacional. Espera-se, desse modo, que os profissionais da área desempenhem "múltiplos papeis" - complexos e, por vezes, contraditórios - assumindo uma postura de parceiro estratégico, facilitador da mudança, representante das pessoas e disseminador das diretrizes institucionais. Ao mesmo tempo, os presidentes entrevistados esperam que a área interfira e auxilie na concepção do plano estratégico da organização.

Com relação às competências requeridas aos profissionais da área, os resultados corroboram achados de pesquisas anteriores que enfatizam a importância do desenvolvimento de capacidades mais abrangentes, notadamente aquelas de caráter social, relacional e comportamental, superando a ênfase em habilidades técnicas e específicas a determinadas áreas de conhecimento. Nessa direção, os entrevistados recomendam o desenvolvimento de três grupos de competências: Cognitivo-emocionais, Relacionais e àquelas associadas ao Negócio e à Estratégia da organização.

Análise comparativa dos resultados revelam desafios, angústias e paradoxos vivenciados pelo $\mathrm{RH}$ contemporâneo. Dentre eles, ainda pairam dúvidas sobre como equilibrar a execução de papeis estratégicos com atividades operacionais; se o profissional de RH deve realizar dadas atividades ou delegá-las a demais áreas da organização; sobre qual identidade o profissional de RH deve assumir (parceiro, fiscalizador, legalista ou agente de mudança). Adiciona-se, a (re-)descoberta de que "gente constitui o objeto da função RH” e de que tal área se encontra em um ponto de inflexão, porém ainda distante de ter promovido um salto qualitativo que a conduzisse a um papel efetivamente estratégico.

\section{REFERÊNCIAS}

ALBUQUERQUE, L. G. Estratégias de Recursos Humanos e competitividade. In: VIEIRA, M. M. F.; OLIVEIRA, L. M. B. (Org.). Administração Contemporânea: perspectivas estratégicas. São Paulo: Atlas, 1999.

BARTLETT, C. A.; GHOSHAL, S. The myth of the generic manager: new personal competencies for new management roles. California Management Review, v. 40, n. 1, p. 93-116, 1987.

BOYATZIS, R. E. The competent manager: a model for effective performance. New York: John Wiley, 1982.

CANÇADO, V. L.; COUTINHO, P. T.; ALMEIDA, M. G. R.; SANT'ANNA, A.S. Novos papeis de Recursos Humanos: Velhas fórmulas em novas embalagens? In: Enanpad, XXIX, 2005, Brasília. Anais... Brasília: Anpad, 2005.

CARRIG, K.;WRIGHT, P. M. Building profit through building people. Society for Human Resource Management, 1-190, 2006. 
CASTRO, J. H. M.; KILIMNIK, Z. M.; SANT’ANNA, A. S. Modernidade organizacional em gestão de pessoas como base para a incorporação de modelo de gestão por competências. Revista de Administração Contemporânea (Eletrônica), 2(1), p. 105-122, 2008.

CESAR, A. M. R. BIDO, Diógenes de Souza. SAAD, S. M. O discurso se Aplica na Prática? - Uma Discussão Sobre o Papel Estratégico da Área de Recursos Humanos. In: Enanpad, 30², 2006, Salvador. Anais... Salvador: Anpad, 2006.

EVANS, P. A. L.; PUCIK, V.; BARSOUX, J.-L. The global challenge: frameworks for international human resource management. New York: McGrawHill. 2002.

FLICK, U. Introdução à pesquisa qualitativa. Porto Alegre: Editora Artmed, 2009.

GIOIA, D. A.; THOMAS, J. B. Identity, Image and issue interpretation: Sensemaking during strategic change in academia, Administrative Science Quarterly, v. 41, pp. 370-403, 1996.

GODOY, A. S. Introdução a pesquisa qualitativa e suas possibilidades. Revista de Administração de Empresas, São Paulo, v.35, n. 2, p. 57-63, mar./abr. 1995.

GREENWOOD, E. Metodos principales de investigacion social empirica. In: Metodologia de la investigacion social. Buenos Aires, cap. 6, p. 106-126, 1973.

GUBMAN, E. HR strategy and planning: from birth to business results. Human Resource Planning, v.27, n.1, p.13-23. 2004.

KILIMNIK, Z. M; SANT'ANNA, A. S.; LUZ, T. R. Competências profissionais e modernidade organizacional: coerência ou contradição?. Revista de Administração de Empresas, Minas Gerais, v. 44. P. 10-21, 2004.

LACOMBE. B. M. B. Políticas e práticas de gestão de pessoas: as abordagens estratégica e institucional. In: Encontro Nacional da ANPAD, 2006, Salvador. Anais..., Salvador, BA, Brasil, 30, 2006.
MINER, J. B.; CRANE, D. P. Human Resource Management: the strategic perspective. New York, Haper Collins, 1995.

PRAHALAD, C. K.; HAMEL, G. The core competence of the corporation. Harvard Business Review, v. 68, n. 3, p. 79-91, May/June 1990.

SANT'ANNA, A. S. Competências individuais requeridas, modernidade organizacional e satisfação no trabalho: uma análise de organizações mineiras sob a ótica de profissionais da área da administração. 2002. 367p. Tese (Doutorado em Administração) - CEPEAD/Universidade Federal de Minas Gerais, Belo Horizonte.

SANTOS, M. O espaço dividido: os dois circuitos da economia urbana dos países subdesenvolvidos, São Paulo: Edusp, 2014.

SILVA, C. L. O.; TORRES, L. M. Gestão de Recursos Humanos: Ser ou Não Ser Estratégica, Eis uma Questão Discursiva. In: III Encontro de Gestão de Pessoas e Relações de Trabalho, $3^{\circ}$, 2011, João Pessoa. Anais... João Pessoa: Anpad, 2011.

STOREY, J. Human resource management: a critical text. London: Routledge, 1995.

SARSUR, A. M.; SANT'ANNA, A. S.; RESENDE, R. P. Onde estão os talentos? Onde está a gestão de recursos humanos? In: XXVII ENANPAD. 2003, Atibaia. Anais... Atibaia: ANPAD, 2003

SPENCER, L. M; SPENCER, S. Competence at work. New York: John Wiley, 1993.

STEFFEN, I. Modelos e competência profissional, 1999. Mimeografado

TANURE, B.; EVANS, P.; PUCIK, V. A gestão de pessoas no Brasil - virtudes e pecados capitais. Rio de janeiro: Campus. 2007. 
TANURE, B.; EVANS, P.; CANÇADO, V. L. As Quatro Faces de RH: Analisando a Performance da Gestão de Recursos Humanos em Empresas no Brasil. Revista de Administração Contemporânea, RAC, Curitiba, v. 14, n. 4, art. 2, p. 594-614, 2010.

TOLFO, S. R.; PICCININI, V. C. A qualidade de vida no trabalho nas melhores empresas para se trabalhar. In: SANT'ANNA, A. S.; KILIMNIK, Z. M. (Orgs.). Qualidade de vida no trabalho: abordagens e fundamentos. Rio de Janeiro: Campus-Elsevier, 2011.
ULRICH, D. Os Campeões de Recursos Humanos: inovando para obter os melhores resultados. São Paulo: Futura, 1998.

YIN, R. K. Estudo de caso: planejamento e métodos. Porto Alegre: Bookman, 2005. 